\title{
Pore Formation Upon Nitriding Iron and Iron-Based Alloys: The Role of Alloying Elements and Grain Boundaries
}

\author{
B. SCHWARZ, H. GÖHRING, S.R. MEKA, R.E. SCHACHERL, and E.J. MITTEMEIJER
}

Pure iron and a series of iron-based $\mathrm{Fe}-\mathrm{Me}$ alloys (with $\mathrm{Me}=\mathrm{Al}, \mathrm{Si}, \mathrm{Cr}, \mathrm{Co}, \mathrm{Ni}$, and $\mathrm{Ge}$ ) were nitrided in a $\mathrm{NH}_{3} / \mathrm{H}_{2}$ gas mixture at $923 \mathrm{~K}\left(650^{\circ} \mathrm{C}\right)$. Different nitriding potentials were applied to investigate the development of pores under ferrite and austenite stabilizing conditions. In all cases, pores developed in the nitrided microstructure, i.e., also and strikingly pure ferritic iron exhibited pore development. The pore development is shown to be caused by the decomposition of (homogeneous) nitrogen-rich $\mathrm{Fe}(-\mathrm{Me})-\mathrm{N}$ phase into nitrogen-depleted $\mathrm{Fe}(-\mathrm{Me})-\mathrm{N}$ phase and molecular $\mathrm{N}_{2}$ gas. The latter, gas phase can be associated with such high pressure that the surrounding iron-based matrix can yield. Thermodynamic assessments indicate that continued decomposition, i.e., beyond the state where yielding is initiated, is possible. Precipitating alloying-element nitrides, i.e., $\mathrm{AlN}, \mathrm{CrN}$, or $\mathrm{Si}_{3} \mathrm{~N}_{4}$, in the diffusion zone below the surface, hinder the formation of pores due to the competition of alloying-element nitride $\left(\mathrm{Me}_{x} \mathrm{~N}_{y}\right)$ precipitation and pore $\left(\mathrm{N}_{2}\right)$ development; alloying elements reducing the solubility of nitrogen enhance pore formation. No pore formation was observed upon nitriding a single crystalline pure iron specimen, nitrided under ferrite stabilizing conditions, thereby exhibiting the essential function of grain boundaries for nucleation of pores.

DOI: $10.1007 / \mathrm{s} 11661-014-2581-\mathrm{x}$

(C) The Minerals, Metals \& Materials Society and ASM International 2014

\section{INTRODUCTION}

NitRIDING is a thermochemical surface treatment applied to improve the mechanical and chemical properties of ferritic steel components. ${ }^{[1-3]}$ The nitrided zone can be subdivided into an outer iron-nitride compound layer, consisting of $\varepsilon-\mathrm{Fe}_{3} \mathrm{~N}_{1+x}$ and/or $\gamma^{\prime}-\mathrm{Fe}_{4} \mathrm{~N}_{1-y}$, on top of a diffusion zone of nitrogen in the ferrite matrix.

The finite rate of nitrogen supply to the specimen surface (owing to the finite rate of dissociation of ammonia at the surface of the specimen, as holds for the usually applied gaseous nitriding processes) is in competition with its inward diffusion into the substrate. Consequently, the concentration of interstitially dissolved nitrogen at the surface, and also in the subsurface regions, of a nitrided pure iron specimen increases gradually as a function of nitriding time (at constant temperature) ${ }^{[4]}$ If the ferrite is alloyed with nitride forming alloying elements, such as $\mathrm{Al}, \mathrm{V}$, and $\mathrm{Cr}$, the inwardly diffusing nitrogen atoms become consumed by alloying-element nitride development, which then governs the shape of the developing nitrogen content depth profile. The precipitated (semi-) coherent nitrides cause

B. SCHWARZ and H. GÖHRING, Ph.D. Students, and S.R. MEKA, Research Scientist, are with the Max Planck Institute for Intelligent Systems (formerly Max Planck Institute for Metals Research), Heisenbergstrasse 3,70569 Stuttgart, Germany. Contact e-mails: s.meka@ is.mpg.de, sairamudu@gmail.com R.E. SCHACHERL, Research Scientist, and E.J. MITTEMEIJER, Professor, Head of Department Phase Transformations, are with the Max Planck Institute for Intelligent Systems (formerly Max Planck Institute for Metals Research), and also with the Institute for Materials Science, University of Stuttgart, Heisenbergstrasse 3, 70569 Stuttgart, Germany

Manuscript submitted January 6, 2014.

Article published online October 3, 2014 a high hardness and a distinct residual stress-depth profile of compressive nature in the surface adjacent region, which effects are responsible for the considerable improvement of especially the mechanical properties, e.g., the fatigue resistance. If the nitriding potential is high enough, then after a certain time, the nitrogen solubility limit of the ferrite matrix is surpassed leading to the nucleation and growth of an iron-nitride compound layer at the surface, which can be associated with significant enhancement of the resistance against wear. ${ }^{[5]}$

Formation of pores in the iron-nitride compound layer is a well-known phenomenon. ${ }^{[6-10]}$ The pores can occur within the grains and along the grain boundaries of the iron-nitride layer. The coalescence of individual pores at the grain boundaries results in opened grain boundaries/ micro-cracks. Pores, in the form of "open" grain boundaries in contact with the outer surface, can be beneficial due to their function as reservoirs for lubricants to provide better tribological performance, ${ }^{[1]}$ but in general pores are detrimental due to the associated mechanical weakening of the material.

Different contradictory mechanisms have been presented in the literature for pore formation in the ironnitride compound layer upon nitriding; see the overview presented in Reference 9. The most widely accepted theory is based on the thermodynamic instability of the iron-nitride phases: ${ }^{[6,7,12]}$ iron-nitride phases which are not in direct contact with the nitriding atmosphere $\left(\mathrm{NH}_{3} / \mathrm{H}_{2}\right.$ gas mixture or nitrogen plasma or salt bath) are, at the usual applied temperatures and pressures, thermodynamically unstable and tend to decompose into molecular $\mathrm{N}_{2}$ gas and iron.

Development of pores upon nitriding is not restricted to the iron-nitride compound layer. Pores can occur as 
well in the diffusion zone, underneath the iron-nitride compound layer, although this has been noticed rarely in the literature: Nitriding of pure iron, employing nitriding parameters (temperature and nitriding potential) corresponding with the austenite phase region of the Lehrer diagram, ${ }^{[13]}$ resulted in the growth of nitrogen austenite from the surface accompanied by the development of pores along the austenite grain boundaries below the surface. ${ }^{[14]}$ Upon prolonged nitriding of ironbased Fe-Me alloys, employing nitriding parameters corresponding with the ferrite phase region of the Lehrer diagram, pores can develop below the surface along grain boundaries in the ferritic matrix. ${ }^{[15-17]}$

In the case of iron-based alloys, the nitrogen absorbed by the specimen can have different chemical states: bonded in the alloying-element nitrides, adsorbed at the nitride platelet faces and dissolved in the matrix. The nitrogen which is responsible for the porosity development is the less strongly bonded dissolved nitrogen. ${ }^{[18]}$

Until now the attention was largely devoted to pore development in the iron-nitride compound layer, whereas little attention was paid on pore development in nitrogen ferrite and nitrogen austenite. Yet, as shown in this work, such pore formation in the nitrogen diffusion zone is a generally occurring phenomenon, leading to pore fractions of possibly 10 vol. pct and more, and thus may have a pronouncedly negative effect on the mechanical properties. As commercial nitriding steels are usually alloyed with a series of alloying elements, it is essential to understand the influence of the dissolved alloying elements and/or the developing alloying-element nitride particles on the pore formation in nitrogen diffusion zones of nitrided steels.

Against the above background, the current project aims at understanding of (i) the development of porosity in pure nitrogen ferrite and in pure nitrogen austenite and (ii) the effects of alloying elements ( $\mathrm{Me}=\mathrm{Al}, \mathrm{Si}$, $\mathrm{Cr}, \mathrm{Co}, \mathrm{Ni}$, and $\mathrm{Ge}$ ) on pore formation in ferrite and austenite. In order to reveal the role of grain boundaries on pore formation, experiments have also been performed on single crystal iron specimens.

\section{THERMODYNAMICS OF GAS NITRIDING AND PORE FORMATION}

At a given temperature, a specific chemical potential of nitrogen in a solid iron-nitrogen phase $\mathrm{Fe}[\mathrm{N}]$ (as $\alpha$-Fe[N] (nitrogen ferrite), $\gamma-\mathrm{Fe}[\mathrm{N}]$ (nitrogen austenite), and the iron nitrides $\gamma^{\prime}-\mathrm{Fe}_{4} \mathrm{~N}_{1-y}$ and $\varepsilon-\mathrm{Fe}_{3} \mathrm{~N}_{1+x}$ ), and thus a certain nitrogen concentration (activity) in the phase concerned, can in principle be realized (actually, at the surface of the solid substrate; see what follows) by imposing an outer gas atmosphere of pure $\mathrm{N}_{2}$ gas at very high pressure. The corresponding equilibrium can be described as:

$$
\frac{1}{2} \mathrm{~N}_{2} \rightleftharpoons[\mathrm{N}]
$$

where $[\mathrm{N}]$ denotes nitrogen dissolved in the solid substrate. The (hypothetical) $\mathrm{N}_{2}$ gas pressures which are needed to establish certain chemical potentials, and thus concentrations of dissolved nitrogen in $\alpha-\mathrm{Fe}[\mathrm{N}]$ or $\gamma-\mathrm{Fe}[\mathrm{N}]$ at a temperature of $923 \mathrm{~K}\left(650{ }^{\circ} \mathrm{C}\right)$ have been plotted in Figure 1. These pressures are (with reasonable effort) technically unfeasible. Therefore, gas nitriding is usually performed with a gas mixture of $\mathrm{NH}_{3}$ and $\mathrm{H}_{2}$ at atmospheric pressure. Upon operating this process, $\mathrm{NH}_{3}$ dissociates at the surface into $\mathrm{H}_{2}$ gas and nitrogen dissolved in the solid substrate. The corresponding equilibrium can be described as:

$$
\mathrm{NH}_{3} \rightleftharpoons[\mathrm{N}]+\frac{3}{2} \mathrm{H}_{2} \text {. }
$$

It is important to realize that establishment of this equilibrium requires that thermal dissociation of $\mathrm{NH}_{3}$ can be ignored and that the recombination of nitrogen atoms adsorbed at the surface is negligible (if the latter would not hold, a stationary state, instead of an equilibrium situation, would occur at the surface of the substrate; for full discussion see References 1, 19).

The equilibrium concentration of dissolved nitrogen in the iron-based $\mathrm{Fe}[\mathrm{N}]$ phase and the nature of this $\mathrm{Fe}[\mathrm{N}]$ phase, (i.e., $\alpha-\mathrm{Fe}[\mathrm{N}], \gamma-\mathrm{Fe}[\mathrm{N}], \gamma^{\prime}-\mathrm{Fe}_{4} \mathrm{~N}_{1-y}$, or $\varepsilon-\mathrm{Fe}_{3} \mathrm{~N}_{1+x}$ ) is determined by the temperature and the chemical potential of nitrogen which is directly proportional to the nitriding potential ${ }^{[20]}$

$$
r_{\mathrm{N}}=\frac{p\left(\mathrm{NH}_{3}\right)}{p\left(\mathrm{H}_{2}\right)^{3 / 2}},
$$

where $p$ is the partial pressure. Thus, the equilibrium nitrogen concentration in the specimen can be easily tuned by adjusting the composition of the nitriding gas atmosphere (see abscissa at the top of Figures 1(a) and (b)).

The $\mathrm{Fe}[\mathrm{N}]$ phase which is not in direct contact with the nitriding gas atmosphere, i.e., the part of the substrate underneath the surface, is unstable with respect to its decomposition into nitrogen-depleted $\mathrm{Fe}[\mathrm{N}]^{*}$ and $\mathrm{N}_{2}$ gas. Thus, in the bulk of nitrogen ferrite and nitrogen austenite the following reactions (Eq. [4] and Eqs. [5a, 5b], respectively) can occur under release of Gibbs energy

$$
\begin{aligned}
& \alpha-\mathrm{Fe}[\mathrm{N}] \rightarrow \alpha-\mathrm{Fe}[\mathrm{N}]^{*}+\mathrm{N}_{2}, \\
& \gamma-\mathrm{Fe}[\mathrm{N}] \rightarrow \gamma-\mathrm{Fe}[\mathrm{N}]^{*}+\mathrm{N}_{2}, \\
& \gamma-\mathrm{Fe}[\mathrm{N}] \rightarrow \alpha-\mathrm{Fe}[\mathrm{N}]^{*}+\mathrm{N}_{2} .
\end{aligned}
$$

The formation of $\mathrm{N}_{2}$ gas can lead to pore development, provided diffusion to an outer surface, not exposed to the nitriding atmosphere, where escape of dissolved nitrogen as $\mathrm{N}_{2}$ gas might occur, can be neglected. Upon this decomposition, the rise of the nitrogen gas pressure in the pores leads to plastic deformation of the surrounding matrix, as follows from the following consideration.

Adopting a spherical shape for a pore (=hollow sphere) yielding of the surrounding pore wall, taken of infinite thickness, occurs if 


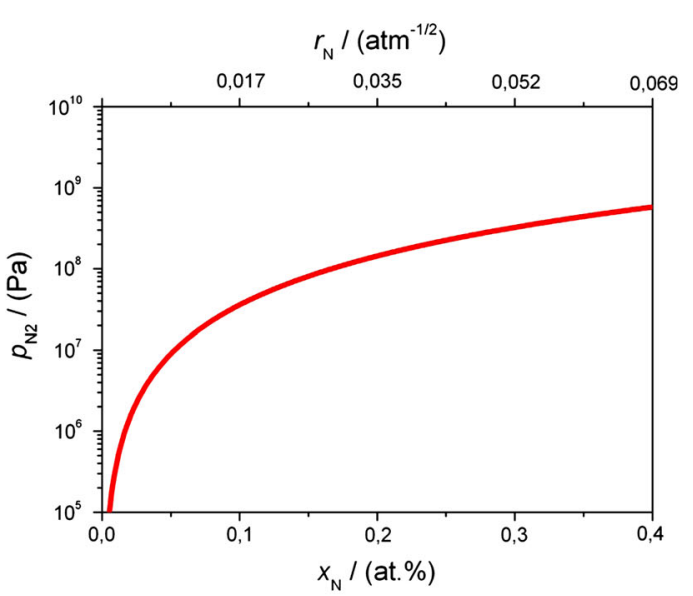

(a)

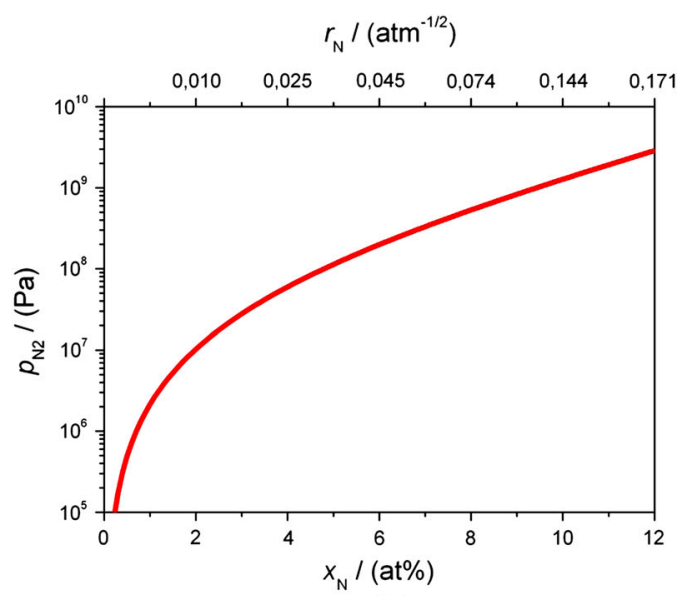

(b)

Fig. 1-The pressure of nitrogen gas $\left(p_{\mathrm{N}_{2}}\right)$ in equilibrium with the iron-nitrogen solid solution as a function of the nitrogen content, $x_{\mathrm{N}}$, at $923 \mathrm{~K}\left(650^{\circ} \mathrm{C}\right)$ for $(a)$ nitrogen ferrite $\left(\alpha-\mathrm{Fe}[\mathrm{N}] ; \mathrm{Fe}+\mathrm{N}_{2} \rightleftharpoons \alpha-\mathrm{Fe}[\mathrm{N}]\right)$ and $(b)$ nitrogen austenite $(\gamma-\mathrm{Fe}[\mathrm{N}] ; \mathrm{Fe}+\mathrm{N} 2 \rightleftharpoons \gamma$-Fe $[\mathrm{N}])$. Note the different nitrogen concentration scales in the diagrams. The nitriding potentials $\left(c f\right.$. Eq. [3]), corresponding to $x_{\mathrm{N}}$, for nitriding in a $\mathrm{NH}_{3} / \mathrm{H}_{2}$ gas mixture at the same temperature and at 1 atm pressure $\left(\mathrm{NH}_{3}+\mathrm{Fe} \rightleftharpoons \alpha-\mathrm{Fe}[\mathrm{N}]+3 / 2 \mathrm{H}_{2} ; \mathrm{NH}_{3}+\mathrm{Fe} \rightleftharpoons \gamma-\mathrm{Fe}[\mathrm{N}]+3 / 2 \mathrm{H}_{2}\right)$, have been indicated on the abscissa at the top of both figures. The values for $p_{\mathrm{N}_{2}}$ as a function of $x_{\mathrm{N}}$ were calculated using the Thermo-Calc software ${ }^{[22]}$ adopting the thermodynamic model for nitrogen in iron presented in Ref. [23].

$$
p_{\mathrm{i}} \geq 2 / 3 \sigma_{\mathrm{y}}
$$

where $p_{\mathrm{i}}$ is the gas pressure in the pore and $\sigma_{\mathrm{y}}$ represents the (uniaxial) tensile yield strength of the matrix. This limiting condition for yielding complies with both the von Mises criterion and the Tresca criterion. ${ }^{[21]}$

Two sets of nitriding parameters were applied in the current work (see Table III). The first set $\left(923 \mathrm{~K}\left(650^{\circ} \mathrm{C}\right)\right.$, $\left.r_{\mathrm{N}}=0.050 \mathrm{~atm}^{-1 / 2}\right)$ stabilizes nitrogen ferrite, $\alpha-\mathrm{Fe}[\mathrm{N}]$, containing 0.35 at. pct nitrogen ${ }^{[19]}$ at the surface of the specimen, corresponding to an (hypothetical) equilibrium $\mathrm{N}_{2}$ gas pressure of $440 \mathrm{MPa}$ (see Figure 1(a), calculated using Thermo-Calc ${ }^{[22]}$ on the basis of a thermodynamic model for nitrogen in iron presented in Reference 23). This equilibrium pressure exceeds $2 / 3$ of the ferrite uniaxial tensile yield strength which equals about $50 \mathrm{MPa}$ at $923 \mathrm{~K}\left(650^{\circ} \mathrm{C}\right) \cdot{ }^{[24]}$ Hence, in view of the inequality [6], the ferrite matrix already yields well before the equilibrium $\mathrm{N}_{2}$ gas pressure in a pore is reached.

The second set of nitriding parameters $(923 \mathrm{~K}$ $\left.\left(650{ }^{\circ} \mathrm{C}\right), r_{\mathrm{N}}=0.104 \mathrm{~atm}^{-1 / 2}\right)$ stabilizes nitrogen austenite, $\gamma-\mathrm{Fe}[\mathrm{N}]$, containing 9.5 at. pct nitrogen ${ }^{[23,25] *}$ at

\footnotetext{
*Instead of the nitriding potential, $r_{\mathrm{N}}$, Thermo-Calc can only handle activities in order to define an equilibrium. To obtain the "activity" of nitrogen, $a_{\mathrm{N}}$, in the gas phase, equal to the activity of nitrogen in the solid, the equilibrium constant of reaction (2) is needed (see Eq. [15] in Ref. [20]). This equilibrium constant was calculated using data taken from Ref. [23]. Knowledge of $a_{\mathrm{N}}, p$, and $T$ then suffices to calculate the corresponding equilibrium concentrations of nitrogen in nitrogen austenite using Thermo-Calc adopting the thermodynamic description in Ref. [23] (the reference state of nitrogen for both phases is taken identical).
}

the surface of the specimen, corresponding to an (hypothetical) equilibrium $\mathrm{N}_{2}$ gas pressure of $1 \mathrm{GPa}$ (see Figure 1(b)). Also in this case, the equilibrium $\mathrm{N}_{2}$ gas pressure exceeds $2 / 3$ of the austenite (uniaxial) tensile yield strength which equals about $570 \mathrm{MPa}^{* *} \cdot{ }^{[26,27]}$ Hence, as

**The (uniaxial) tensile yield strength of austenite containing 9.5 at. pct nitrogen was calculated applying the formula presented in Ref. [26] which is valid at a temperature of $295 \mathrm{~K}\left(22^{\circ} \mathrm{C}\right)$. For higher temperatures, the tensile yield strength becomes significantly smaller and is above $450^{\circ} \mathrm{C}$ nearly constant ${ }^{[27]}$. The relative decrease of the yield strength from RT to $450^{\circ} \mathrm{C}$ is almost independent of the nitrogen content in austenitic steels. ${ }^{[27]}$ Therefore, the calculated value for the tensile yield strength at $295 \mathrm{~K}\left(22{ }^{\circ} \mathrm{C}\right)$ was multiplied with this factor to estimate the tensile yield strength of austenite containing 9.5 at. pct nitrogen at $923 \mathrm{~K}\left(650^{\circ} \mathrm{C}\right)$.

for ferrite upon nitriding, in view of the inequality,[6] the austenite matrix already yields well before the equilibrium $\mathrm{N}_{2}$ gas pressure in a pore is reached.

Starting with, respectively, nitrogen ferrite containing 0.35 at. pct nitrogen and nitrogen austenite containing 9.5 at. pct nitrogen (see above), the Gibbs energy differences for the decomposition reactions [4], [5a] and [5b] and the nitrogen concentrations left in the depleted matrix $\left(\mathrm{Fe}[\mathrm{N}]^{*}\right)$ were calculated, using approaches presented in Reference 23, for the inner pore, nitrogen gas pressures at which the iron matrix starts to yield. The results have been gathered in Table I.

In the cases of the decomposition of $\alpha-\mathrm{Fe}[\mathrm{N}]$ according to Eq. [4] and the decomposition of $\gamma-\mathrm{Fe}[\mathrm{N}]$ according to Eq. [5a], further decomposition (i.e., after the onset of yielding) is thermodynamically favored as the corresponding Gibbs energy differences at the onset of yielding are negative ( $c f$. Table I).

The decomposition of $\gamma-\mathrm{Fe}[\mathrm{N}]$ into $\alpha-\mathrm{Fe}[\mathrm{N}]^{*}$ (Eq. [5b]) and $\mathrm{N}_{2}$ gas in closed pores is only thermodynamically possible below nitrogen gas pressures (in the pores) of $330 \mathrm{MPa}$ (then the Gibbs reaction energy is negative). Therefore, the decomposition of $\gamma-\mathrm{Fe}[\mathrm{N}]$ into 
Table I. The Gibbs Reaction Energies $\Delta G$ (if $\Delta G<0$, Energy is Released), of Reactions [4], [5a] and [5b] at $923 \mathrm{~K}\left(650{ }^{\circ} \mathrm{C}\right)$ are Given for Two Nitriding Potentials $\left(r_{N}\right.$; the Nitriding Potential Tunes at a Given Temperature the Equilibrium Nitrogen Concentration in Iron $\left.\left(c_{\mathrm{N}}\right)\right)$, as Applied in This Work, and the Pressure, $p_{\mathrm{i}}$, Where Yielding of the Matrix Surrounding the Pore is Initiated $\left(p_{i}=2 / 3 \sigma_{y}{ }^{[21]}\right.$ Where $p_{i}$ is the Nitrogen Gas Pressure in the Pore and $\sigma_{y}$ is the (Uniaxial) Tensile Yield Strength of Ferrite ${ }^{[24]}$ or Nitrogen Austenite ${ }^{[26,27]}$ )

\begin{tabular}{|c|c|c|c|}
\hline$r_{\mathrm{N}}\left(\mathrm{atm}^{-1 / 2}\right)$ & 0.050 & \multicolumn{2}{|c|}{0.104} \\
\hline$p_{i}(\mathrm{MPa})$ & 33 & \multicolumn{2}{|c|}{380} \\
\hline$c_{\mathrm{N}}(\mathrm{Fe}[\mathrm{N}])($ at. pct) & 0.35 & \multicolumn{2}{|c|}{9.50} \\
\hline$c^{*}{ }_{N}\left(\mathrm{Fe}[\mathrm{N}]^{*}\right)($ at. pct $)$ & 0.10 & 7.28 & 0.32 \\
\hline Reaction & {$[4]$} & {$[5 a]$} & {$[5 \mathrm{~b}]$} \\
\hline$\Delta G(\mathrm{~J} / \mathrm{mol})$ & -17 & -47 & 47 \\
\hline
\end{tabular}

The nitrogen concentration, $c^{*} \mathrm{~N}$, in the nitrogen-depleted iron of reactions [4], [5a] and [5b] is shown as well.

$\alpha-\mathrm{Fe}[\mathrm{N}]^{*}$ can in principle occur but the release of Gibbs free energy for the decomposition of $\gamma-\mathrm{Fe}[\mathrm{N}]$ into $\gamma$-Fe[N]* (Eq. [5a]) is larger at the considered conditions, and thus is thermodynamically favored.

\section{EXPERIMENTAL PROCEDURES}

\section{A. Specimen Preparation}

Several iron-based alloys were prepared from elemental granules of Fe (purity $99.98 \mathrm{wt}$ pct), Al (purity 99.999 wt pct), Si (purity 99.999 wt pct), Cr (purity 99.98 wt pct), Co (purity 99.98 wt pct), Ni (purity 99.98 wt pct), and Ge (purity 99.999 wt pct). The granules were melted in an induction furnace under a protective Ar atmosphere and cast to rods with a length of $100 \mathrm{~mm}$ and a diameter of $10 \mathrm{~mm}$. The cast rods were ground to remove surface oxides and cleaned in ethanol in an ultrasonic bath, and thereafter cold-rolled to sheets of approximately $1 \mathrm{~mm}$ thickness. Rectangular specimens $(15 \times 10 \times 1) \mathrm{mm}$ were cut from such coldrolled sheets. These specimens were ground and polished (final stage with $1 \mu \mathrm{m}$ diamond paste) from both sides and ultrasonically cleaned in ethanol. The specimens were then encapsulated in a quartz tube under protective Ar atmosphere and recrystallized at $1073 \mathrm{~K}\left(800{ }^{\circ} \mathrm{C}\right)$ for 20 minutes. After the recrystallization treatment, the specimens were polished (again) with $1 \mu \mathrm{m}$ diamond paste to remove surface oxides, which might have formed during the recrystallization treatment, and ultrasonically cleaned in ethanol.

In order to determine the amounts of alloying elements in samples taken from the produced casts, inductively coupled plasma optical emission spectroscopy (ICP-OES) was applied, whereas carrier gas hot extraction was used to determine the amount of light element impurities such as $\mathrm{O}$ and $\mathrm{N}$. The amounts of $\mathrm{C}$ and $\mathrm{S}$ were determined by means of the combustion method. Results of the chemical analysis for Fe and the iron-based alloy casts are shown in Table II.

\section{B. Nitriding}

The gas nitriding facility consists of a vertical multizone quartz tube furnace (diameter $28 \mathrm{~mm}$ ) and is equipped with temperature controllers (temperature variation $\pm 1{ }^{\circ} \mathrm{C}$ ) and gas mass-flow controllers. For the nitriding treatments, the sheet specimens (see above) were suspended with a quartz fiber and positioned in the uniform temperature zone of the furnace. The sum of the gas fluxes of $\mathrm{NH}_{3}$ (purity $99.998 \mathrm{vol}$ pct) and $\mathrm{H}_{2}$ (purity $99.999 \mathrm{vol}$ pct) were kept constant at $500 \mathrm{~mL} /$ min and the $\mathrm{NH}_{3}$ and $\mathrm{H}_{2}$ gas fluxes were maintained such to set the required nitriding potential. ${ }^{[20]}$ Nitriding experiments were carried out such that either nitrogen ferrite or nitrogen austenite was stabilized at the specimen's surface. The corresponding two sets of nitriding conditions employed in the present work are shown in Table III. The nitriding treatment was interrupted by quenching the specimens into water which was purged with $\mathrm{N}_{2}$ gas to minimize the amount of dissolved oxygen.

\section{Weight Measurement}

Specimens were weighed before nitriding and after homogenous (through) nitriding, and the weight uptake was used to calculate the nitrogen uptake of the specimens. Five weight measurements were carried out and from the mean, the average nitrogen content and its standard deviation were calculated. For weighing, a comparator balance (Mettler XP56) with $1 \mu \mathrm{g}$ $(0.001 \mathrm{mg})$ sensitivity was used.

\section{X-Ray Diffraction}

A PANalytic X'Pert MPD (multi-purpose diffractometer) was used to characterize the phases developed after nitriding. Co- $\mathrm{K}_{\alpha}$ radiation and Bragg-Brentano geometry with a graphite monochromator in the diffracted beam and a PANalytical $X^{\prime}$ Celerator detector were employed. The specimens were rotated around their surface normal during the measurements to enhance crystal statistics. The recorded XRD-patterns were analyzed by using the software X'Pert HighScore and the different phases were identified using the database from the International Center for Diffraction Data (ICDD). ${ }^{[28]}$

\section{E. Light Microscopy}

Specimens for light microscopical analysis were cut perpendicular to the nitrided surface and embedded in Struers Polyfast to obtain cross-sections. The embedded cross-sections were ground, polished (final stage $1 \mu \mathrm{m}$ diamond paste) and etched with 2 vol pct Nital for 
Table II. Alloying Element and Light Element Impurity Contents in the Pure Iron and the Binary Iron-Based Fe-Me Alloy Casts Used in the Present Work

\begin{tabular}{|c|c|c|c|c|c|c|}
\hline Alloy & Alloying Element (wt pct) & Alloying Element (at. pct) & $\mathrm{O}(\mu \mathrm{g} / \mathrm{g})$ & $\mathrm{N}(\mu \mathrm{g} / \mathrm{g})$ & $\mathrm{C}(\mu \mathrm{g} / \mathrm{g})$ & $\mathrm{S}(\mu \mathrm{g} / \mathrm{g})$ \\
\hline $\mathrm{Fe}$ & - & - & 70 & $<10$ & $<10$ & $<10$ \\
\hline $\mathrm{Fe}-\mathrm{Al}$ & $0.95 \pm 0.01$ & $1.95 \pm 0.02$ & 20 & $<5$ & $<10$ & $<10$ \\
\hline $\mathrm{Fe}-\mathrm{Si}$ & $1.01 \pm 0.01$ & $1.99 \pm 0.02$ & 30 & $<20$ & $<10$ & $<20$ \\
\hline $\mathrm{Fe}-\mathrm{Cr}$ & $1.90 \pm 0.02$ & $2.08 \pm 0.02$ & 24 & $<10$ & $<20$ & $<20$ \\
\hline $\mathrm{Fe}-\mathrm{Co}$ & $2.13 \pm 0.02$ & $2.02 \pm 0.02$ & 20 & $<10$ & $<20$ & $<20$ \\
\hline $\mathrm{Fe}-\mathrm{Ni}$ & $2.12 \pm 0.02$ & $2.02 \pm 0.02$ & 35 & $<10$ & $<20$ & $<20$ \\
\hline $\mathrm{Fe}-\mathrm{Ge}$ & $2.17 \pm 0.02$ & $1.76 \pm 0.02$ & 50 & $<10$ & $<35$ & $<20$ \\
\hline
\end{tabular}

Table III. Nitriding Parameters Employed to Stabilize Either Nitrogen Ferrite, $\alpha$-Fe[N], or Nitrogen Austenite, $\gamma$-Fe[N], at the Surface of the Specimen

\begin{tabular}{|c|c|c|c|c|c|}
\hline \multirow[b]{2}{*}{ Phase at Specimen Surface } & \multirow[b]{2}{*}{ Temperature $\left[\mathrm{K}\left({ }^{\circ} \mathrm{C}\right)\right]$} & \multicolumn{2}{|c|}{$\begin{array}{l}\text { Flow Rate } \\
\text { (mL/minute) }\end{array}$} & \multirow[b]{2}{*}{$r_{\mathrm{N}}\left(\operatorname{atm}^{-1 / 2}\right)$} & \multirow[b]{2}{*}{ Time (hour) } \\
\hline & & $\mathrm{NH}_{3}$ & $\mathrm{H}_{2}$ & & \\
\hline$\alpha-\mathrm{Fe}[\mathrm{N}]$ & $923(650)$ & 23.25 & 476.75 & 0.050 & 72 \\
\hline$\gamma-\mathrm{Fe}[\mathrm{N}]$ & $923(650)$ & 45.00 & 455.00 & 0.104 & 72 \\
\hline
\end{tabular}

30 seconds. A Zeiss Axiophot microscope, equipped with an Olympus Color View IIIu digital camera, was used to record the microstructures. In order to determine the void fraction in the nitrided region, 10 images were recorded from different, randomly selected regions of the nitrided volume (each image covers a rectangular area of $\left.(440 \times 100) \mu \mathrm{m}^{2}\right)$ and the area fraction of the pores was determined by using the software analySIS 5.0 from Soft Imaging System. The area fraction of the pores is equal to the volume fraction of the pores if the pores do not exhibit a morphological texture. ${ }^{[29]}$

\section{F. Scanning Electron Microscopy (SEM) and Electron Backscatter Diffraction (EBSD)}

A LEO $1530 \mathrm{VP}$ (acceleration voltage $3 \mathrm{kV}$, working distance $6 \mathrm{~mm}$ ) equipped with an in-lens detector (30 $\mathrm{mm}$ aperture) was applied to record SEM micrographs. EBSD investigation was carried out to determine the distribution, shape, and crystal orientation of the phases present in a specimen's cross-section. To this end, a Zeiss LEO 438 VP scanning electron microscope (acceleration voltage $20 \mathrm{kV}$ ) equipped with a high-speed camera from EDAX and the analyzing software OIM 5.31 from TSL was employed.

\section{G. Electron Probe Microanalysis (EPMA)}

In order to determine local chemical compositions, point scans were performed using the SX100 microanalyzer from Cameca. Cross-sections for analysis were prepared in a similar way as for light microscopy except that the final etching step was omitted. A focused electron beam of acceleration voltage of $15 \mathrm{kV}$ and current of $100 \mathrm{nA}$ was employed. The intensities of generated characteristic $\mathrm{N}-\mathrm{K}_{\alpha}$, and $\mathrm{Fe}-\mathrm{K}_{\beta} \mathrm{X}$-ray emission peaks were used to obtain the element concentrations of $\mathrm{N}$ and $\mathrm{Fe}$, respectively: The measured $\mathrm{N}-\mathrm{K}_{\alpha}$, and $\mathrm{Fe}-\mathrm{K}_{\beta}$ intensities were divided by the intensities recorded from $\gamma^{\prime}-\mathrm{Fe}_{4} \mathrm{~N}\left(\mathrm{~N}-\mathrm{K}_{\alpha}\right)$ and $\mathrm{Fe}$ $\left(\mathrm{Fe}-\mathrm{K}_{\beta}\right)$ standard specimens, respectively, and the concentration values were calculated from these intensity ratios applying the $\phi(\rho z)$-approach according to Reference 30 .

\section{RESULTS}

\section{A. Pore Formation in Nitrogen Ferrite and the Role of Alloying Elements}

Microstructures of the nitrided regions as developed in pure iron and the binary iron-based Fe-Me alloys nitrided for 72 hours under conditions which, at least for pure iron (see what follows), stabilize the ferrite phase at the surface of the specimen $\left[923 \mathrm{~K}\left(650{ }^{\circ} \mathrm{C}\right), r_{\mathrm{N}}=0.050 \mathrm{~atm}^{-1 / 2}\right.$; $c f$. Reference 13] are shown in Figure 2. The amount of nitrogen taken up by the specimens upon nitriding (cf. Section III-C) and the resulting pore fractions (cf. Section III-E) have been gathered in Table IV.

The micrographs reveal the development of porosity along grain boundaries of the ferrite matrix. The amount of porosity in the alloys shows a strong dependence on the presence and the type of alloying element: $\mathrm{Fe}-\mathrm{Ni}$ and $\mathrm{Fe}-\mathrm{Ge}$ alloys show the highest porosity; pure iron and $\mathrm{Fe}-\mathrm{Cr}$ and $\mathrm{Fe}-\mathrm{Co}$ alloys take an intermediate position and the lowest porosity can be detected in Fe-Al and Fe-Si alloys (see Figure 2 and Table IV). The shape, size and density of the pores nucleating at the grain boundaries are largely determined by the nature and geometrical arrangement of the grain boundaries which is a function of grain size and grain shape (e.g., the pore nucleated at a grain boundary junction could have three legged morphology). It can further be expected that anisotropy of surface energy can in principle induce a facetted appearance of a pore.

The X-ray diffractograms recorded from the surface of the iron and iron-based Fe-Me alloy specimens after the nitriding treatment are shown in Figure 3. Except 


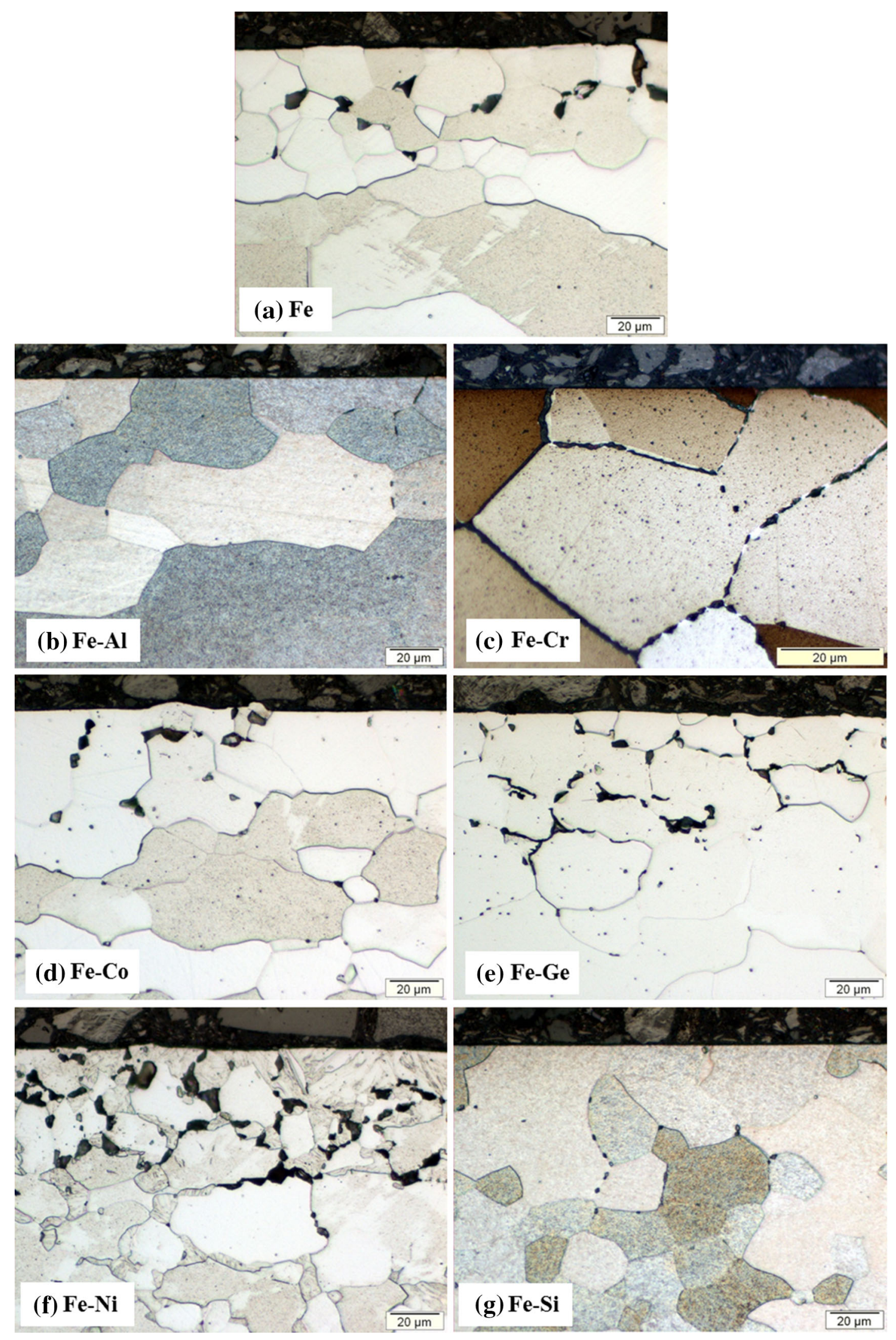

Fig. 2-Microstructures for nitrogen-ferrite stabilizing conditions. Light optical micrographs recorded from cross-sections (polished and etched) of iron and iron-based Fe-Me alloy specimens after nitriding for $72 \mathrm{~h}$ at $923 \mathrm{~K}\left(650^{\circ} \mathrm{C}\right)$ and with $r_{\mathrm{N}}=0.050 \mathrm{~atm}^{-1 / 2}$. The amount of pores is small in the $\mathrm{Fe}-\mathrm{Al}$ and $\mathrm{Fe}-\mathrm{Si}$ alloys, moderate in pure $\mathrm{Fe}$ and the $\mathrm{Fe}-\mathrm{Cr}$ and $\mathrm{Fe}-\mathrm{Co}$ alloys, and large in the $\mathrm{Fe}-\mathrm{Ni}$ and $\mathrm{Fe}-\mathrm{Ge}$ alloys. Note that the $\mathrm{Fe}-\mathrm{Ni}$ alloy became austenitic in the surface region upon nitriding (see text). 
Table IV. Pore Fraction and Nitrogen Content Resulting by Nitriding Under Nitrogen-Ferrite Stabilizing Condition [923 K $\left(650{ }^{\circ} \mathrm{C}\right)$ Using $r_{\mathrm{N}}=0.050 \mathrm{~atm}^{-1 / 2}$ ] for Pure Iron and Several Iron-Based Fe-Me Alloys, all (Through) Nitrided for $72 \mathrm{~h}$

\begin{tabular}{|c|c|c|c|c|c|c|c|}
\hline Alloy & $\mathrm{Fe}$ & $\mathrm{Fe}-\mathrm{Al}$ & $\mathrm{Fe}-\mathrm{Cr}$ & $\mathrm{Fe}-\mathrm{Co}$ & $\mathrm{Fe}-\mathrm{Ge}$ & $\mathrm{Fe}-\mathrm{Si}$ & $\mathrm{Fe}-\mathrm{Ni}$ \\
\hline Pore fraction (pct) & 0.55 & $<0.1$ & 0.51 & 0.52 & 2.13 & $<0.1$ & 4.20 \\
\hline $\mathrm{N}$ Content (at. pct) & 0.31 & 2.39 & 2.18 & 0.26 & 0.23 & 0.24 & 0.99 \\
\hline$M e_{x} \mathrm{~N}_{y}$ & - & AlN & $\mathrm{CrN}$ & $\mathrm{Co}_{3} \mathrm{~N}$ & $\beta-\mathrm{Ge}_{3} \mathrm{~N}_{4}$ & $\beta-\mathrm{Si}_{3} \mathrm{~N}_{4}$ & $\mathrm{Ni}_{3} \mathrm{~N}$ \\
\hline$\Delta G_{f}^{\circ}\left(M e_{x} \mathrm{~N}_{y}\right) /(\mathrm{kJ} / \mathrm{mol})$ & - & -574 & -185 & $\sim 0$ & -153 & -358 & $\sim 0$ \\
\hline Volume Misfit ${ }^{*}(\mathrm{pct})$ & - & 77 & 52 & 13 & 143 & 105 & 13 \\
\hline
\end{tabular}

Additionally, the stoichiometry of the possibly precipitating alloying-element nitrides, their standard Gibbs energy of formation, $\Delta G_{f}^{\circ}$ (at $298 \mathrm{~K}$ $\left(25^{\circ} \mathrm{C}\right.$ ), for the reaction of $1 \mathrm{~mol}$ of $\left.\mathrm{N}_{2}\right)$, and their volume misfit with the ferrite matrix have been indicated.

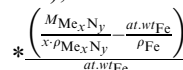
100 , where $M, \rho$ and at.wt are molecular mass, density, and atomic mass, respectively.

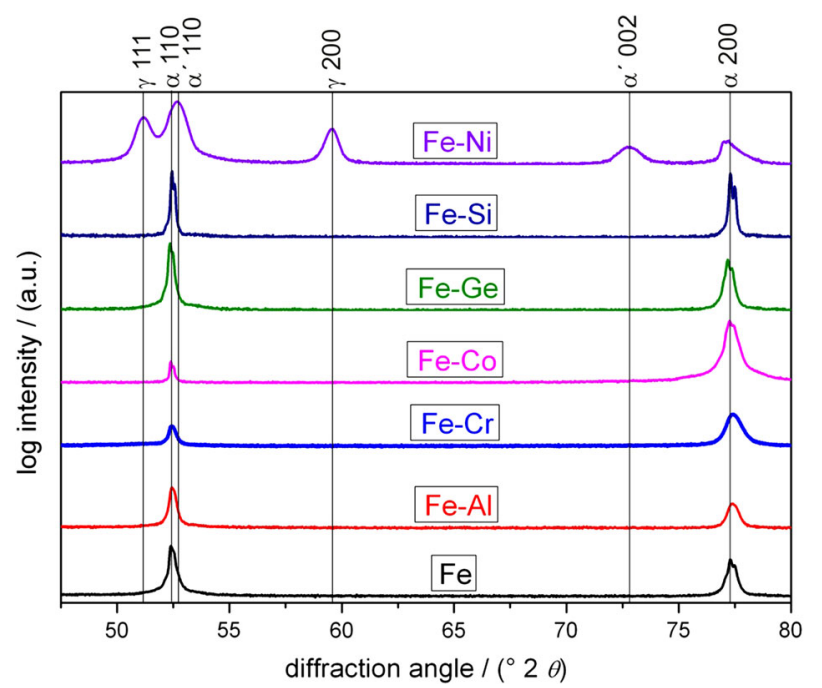

Fig. 3-X-ray diffractograms $\left(\mathrm{Co}-\mathrm{K}_{\alpha}\right)$ recorded from the surface of pure iron and iron-based Fe-Me alloy specimens after nitriding for $72 \mathrm{~h}$ at $923 \mathrm{~K}\left(650^{\circ} \mathrm{C}\right)$ and with $r_{\mathrm{N}}=0.050 \mathrm{~atm}^{-1 / 2}$. Except in case of the Fe-Ni alloy, only reflections from ferrite are observed. The diffractogram of the nitrided $\mathrm{Fe}-\mathrm{Ni}$ alloy shows, in addition to ferrite $(\alpha)$ reflections, reflections belonging to nitrogen austenite $(\gamma)$, and nitrogen martensite $\left(\alpha^{\prime}\right)$.

for the Fe-Ni alloy, the diffractograms of the nitrided specimens show only ferrite reflections. In case of the $\mathrm{Fe}-\mathrm{Ni}$ alloy, in addition to ferrite reflections, reflections belonging to nitrogen austenite and nitrogen martensite were detected.

The microstructures as developed close to the surface of polycrystalline pure iron and polycrystalline binary $\mathrm{Fe}-\mathrm{Co}$ and $\mathrm{Fe}-\mathrm{Ge}$ alloy specimens are shown in Figure 4. It is observed that the development of pores (along ferrite grain boundaries) in the polycrystalline iron and polycrystalline $\mathrm{Fe}-\mathrm{Me}$ alloys is associated with bulging out of the ferrite matrix on top of the pores. In contrast with the polycrystalline specimens, a single crystalline iron specimen shows no porosity at all - even, as revealed by additional experiments, after a nitriding time much longer than that for the polycrystalline specimens (Figure 4(b)).

\section{B. Pore Formation in Nitrogen Austenite and the Role of Alloying Elements}

Microstructures of the nitrided regions developed in the, initially ferritic, pure iron and binary iron-based $\mathrm{Fe}-\mathrm{Me}$ alloy specimens, nitrided for 72 hours under conditions which stabilize the nitrogen austenite phase at the surface of the specimens $\left(923 \mathrm{~K}\left(650^{\circ} \mathrm{C}\right), r_{\mathrm{N}}=0.104 \mathrm{~atm}^{-1 / 2} ; c f\right.$. Reference 13), are shown in Figures 5 and 6. The amount of nitrogen taken up by the specimens upon nitriding (cf. Section III-C) and the resulting pore fractions ( $c f$. Section III-E) have been gathered in Table V.

The nitrided polycrystalline iron specimen shows isolated pores as well as channels of coalesced pores along grain boundaries which are more or less perpendicular to the surface (Figure 5(a)). Some of these channels are in direct contact with the outer surface. The microstructure in the surface adjacent region, as exposed by the EBSD phase map (Figures 5(b) and (c)), consists of a relatively thin surface adjacent zone dominantly composed of nitrogen austenite $(\gamma-\mathrm{Fe}[\mathrm{N}]$; indicated by green color). A zone of dominantly nitrogen martensite ( $\alpha^{\prime}$; indicated by dark red color) occurs at larger depth, followed by a core of nitrogen ferrite $(\alpha-\mathrm{Fe}[\mathrm{N}]$; indicated by bright red color). The presence of nitrogen austenite at the very surface is confirmed by XRD-phase analysis (see the diffractogram at the bottom of Figure 7). Pores which have developed in this region are surrounded by nitrogen austenite and nitrogen martensite as indicated by EBSD (see Figure 5(c)). Local nitrogen concentrations, as determined by EPMA (point) measurements (see concentration indications in Figure 5(c)), confirm the presence of nitrogen austenite/ martensite adjacent to the pores: the nitrogen concentrations are much too high for nitrogen ferrite. Beneath the region exhibiting channels, a needle-like microstructure (see Figure 5(a)) consisting nearly exclusively of nitrogen martensite (see Figure 5(b)) has formed from nitrogen austenite upon water quenching, applied after completion of the nitriding time (see Section III-B).

Except the Fe-Si alloy, all nitrided (initially ferritic) Fe-Me alloys showed distinct porosity development (Figure 6) and a layer consisting of nitrogen austenite and nitrogen martensite ( $c f$. insets in Figure 6 and diffractograms in Figure 7). The largest amount of porosity has been generated in the nitrided Fe-Ge alloy 

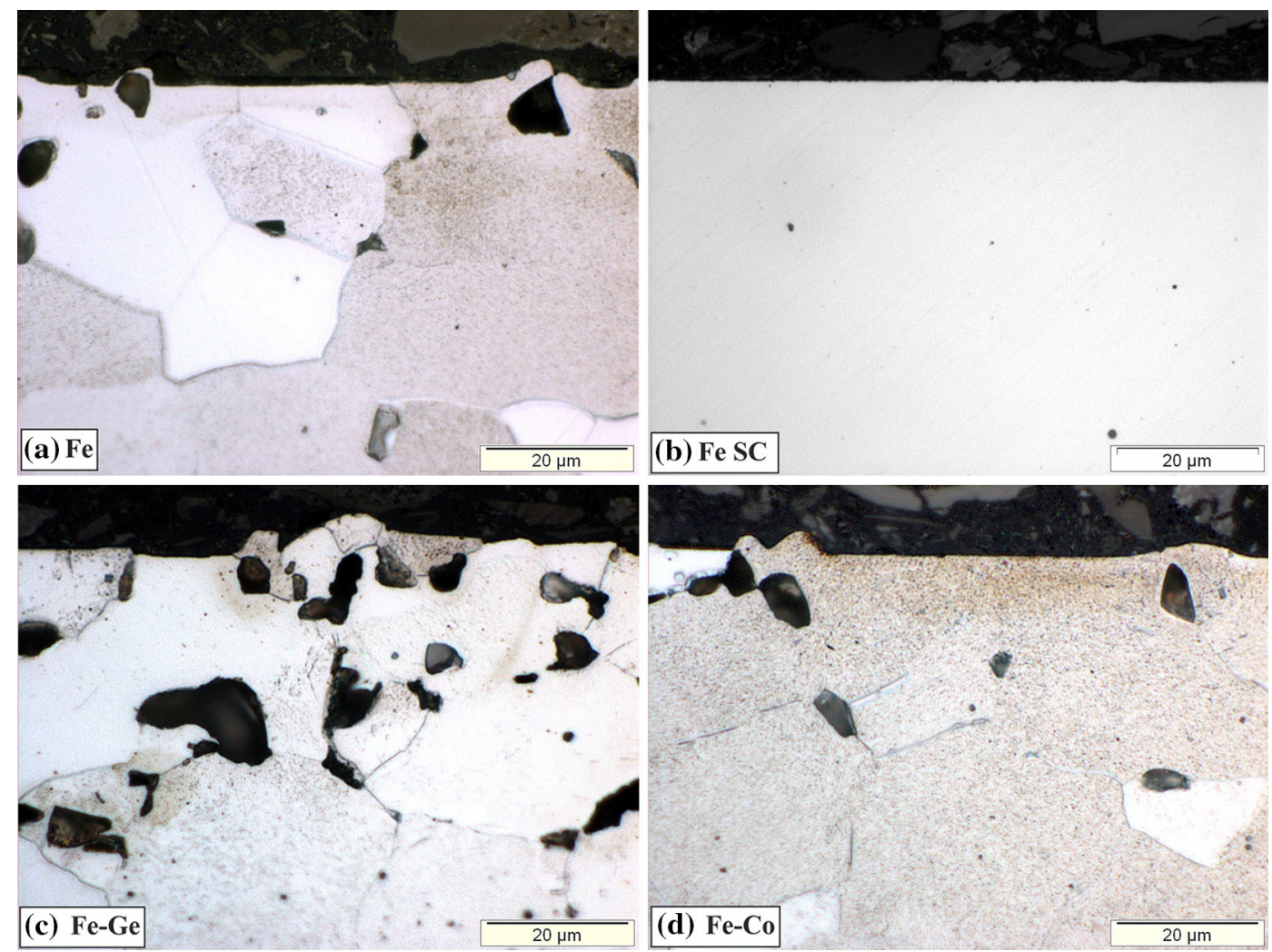

Fig. 4-Light optical micrographs recorded from cross-sections of iron and iron-based, ferritic specimens after nitriding for $72 \mathrm{~h}$ at $923 \mathrm{~K}$ $\left(650{ }^{\circ} \mathrm{C}\right)$ with $r_{\mathrm{N}}=0.050 \mathrm{~atm}^{-1 / 2}$. (a) Polycrystalline iron, (b) Single crystal of iron nitrided for $168 \mathrm{~h}(72+96 \mathrm{~h})$ applying the conditions as above, which shows no pore formation (cross-section was only polished). (c) Fe-Ge alloy and (d) Fe-Co alloy. Pores which developed close to the surface in polycrystalline iron and $\mathrm{Fe}-\mathrm{Ge}$ and $\mathrm{Fe}-\mathrm{Co}$ alloys caused bulging out of material at locations of the surface close to these pores.

Table V. Pore Fraction and Nitrogen Content Resulting by Nitriding Under Nitrogen-Austenite Stabilizing Condition [923 K $\left(650{ }^{\circ} \mathrm{C}\right)$ Using $r_{\mathrm{N}}=0.104 \mathrm{~atm}^{-1 / 2}$ for Pure Iron and Several Iron-Based Fe-Me Alloys, all Nitrided for $72 \mathrm{~h}$

\begin{tabular}{|c|c|c|c|c|c|c|c|}
\hline Alloy & $\mathrm{Fe}$ & $\mathrm{Fe}-\mathrm{Al}$ & $\mathrm{Fe}-\mathrm{Cr}$ & $\mathrm{Fe}-\mathrm{Co}$ & $\mathrm{Fe}-\mathrm{Ge}$ & $\mathrm{Fe}-\mathrm{Si}$ & $\mathrm{Fe}-\mathrm{Ni}$ \\
\hline Pore Fraction (Percent) & 4.79 & 0.97 & 2.30 & 13.90 & 17.03 & - & 8.68 \\
\hline N Content (at. pct) & 3.67 & 2.62 & 3.33 & 0.35 & 0.57 & 0.83 & 2.74 \\
\hline$M e_{x} \mathrm{~N}_{y}$ & - & AlN & $\mathrm{CrN}$ & $\mathrm{Co}_{3} \mathrm{~N}$ & $\beta-\mathrm{Ge}_{3} \mathrm{~N}_{4}$ & $\beta-\mathrm{Si}_{3} \mathrm{~N}_{4}$ & $\mathrm{Ni}_{3} \mathrm{~N}$ \\
\hline$\Delta G_{f}^{\circ}\left(\mathrm{Me}_{x} \mathrm{~N}_{y}\right)(\mathrm{kJ} / \mathrm{mol})$ & - & -574 & -185 & $\sim 0$ & -153 & -358 & $\sim 0$ \\
\hline Volume Misfit (Percent) & - & -8 & -21 & -42 & 26 & 6 & -42 \\
\hline
\end{tabular}

Additionally, the stoichiometry of the possibly precipitating alloying-element nitrides and their standard Gibbs energy of formation, $\Delta G_{f}^{\circ}$ [at $298 \mathrm{~K}\left(25^{\circ} \mathrm{C}\right)$ for the reaction of $1 \mathrm{~mol}$ of $\mathrm{N}_{2}$ ], and their volume misfit with the austenite matrix have been indicated.

(see also Table V). In this alloy pores have developed which often exhibit a more globular shape and have diameters of several micrometers ( $c f$. Figure 6(d)). The nitrided Fe-Si alloy does not show pore development and, also in contrast with the other nitrided Fe-Me alloys and nitrided iron under these conditions, its surface adjacent region consists of nitrogen ferrite and not of nitrogen austenite ( $c f$. X-ray diffractograms in Figure 7), instead the Fe-Si alloy showed development of bands (of $\mathrm{Si}_{3} \mathrm{~N}_{4}$; see Section $\mathrm{V}-\mathrm{B}$ ) along ferrite grain boundaries and cubical $\left(\mathrm{Si}_{3} \mathrm{~N}_{4}\right.$; see Section $\left.\mathrm{V}-\mathrm{B}\right)$ particles within ferrite grains (Figures $6(\mathrm{~g}),(\mathrm{h})$ )

The thickness of the nitrogen austenite/martensite-surface layer after nitriding is different in the various $\mathrm{Fe}-\mathrm{Me}$ alloys. The thickness of the nitrogen austenite/martensitesurface layer is very thin in case of $\mathrm{Fe}-\mathrm{Al}, \mathrm{Fe}-\mathrm{Cr}, \mathrm{Fe}-\mathrm{Co}$, and Fe-Ge alloys, whereas a thick austenite/martensite-surface layer occurs in case of the Fe-Ni alloy and pure iron.

\section{DISCUSSION}

\section{A. Pore Formation in Nitrogen Ferrite and the Role of} Alloying Elements

The applied nitriding time of 72 hours at $923 \mathrm{~K}\left(650{ }^{\circ} \mathrm{C}\right)$ with $r_{\mathrm{N}}=0.050 \mathrm{~atm}^{-1 / 2}$ is sufficient to homogeneously (through) nitride the ferritic matrix of the 1.0-mm-thick 

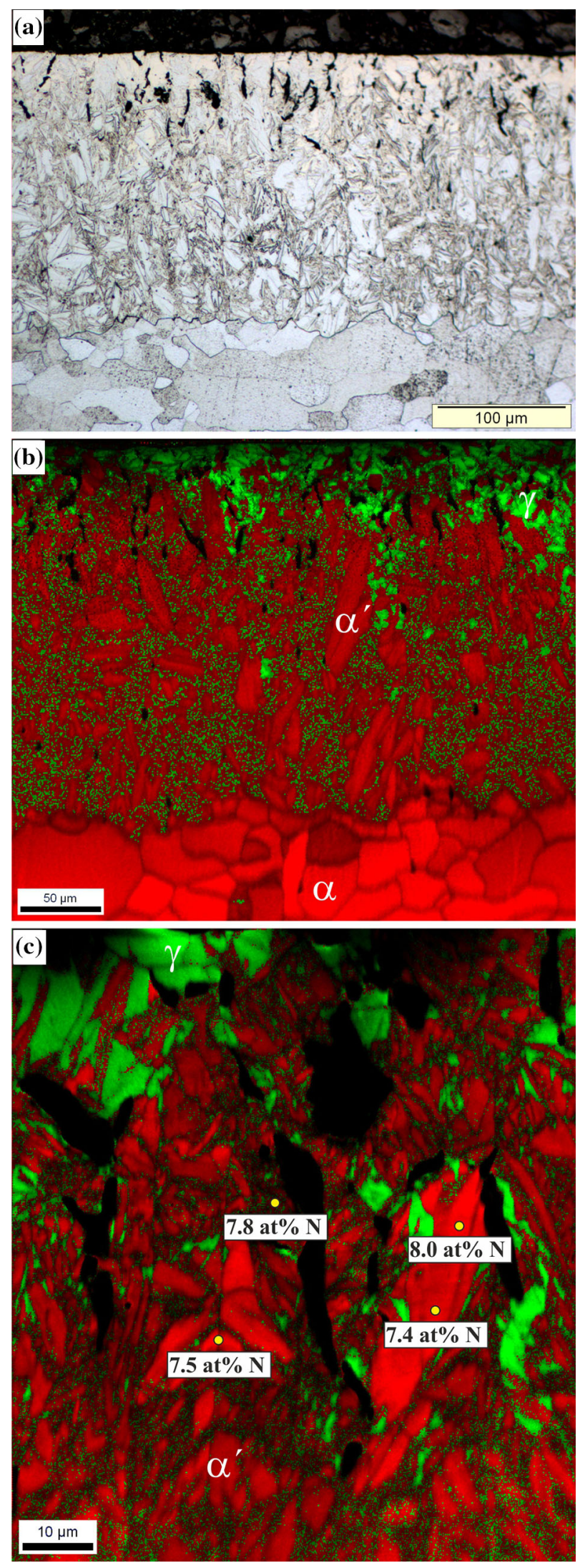

Fig. 5- (a) Light optical micrograph recorded from the cross-section (polished and etched) of a polycrystalline iron specimen nitrided at $923 \mathrm{~K}\left(650{ }^{\circ} \mathrm{C}\right)$ for $72 \mathrm{~h}$ with $r_{\mathrm{N}}=0.104 \mathrm{~atm}^{-1 / 2}$. Channels of coalesced pores, oriented more or less perpendicular to the surface, can be observed. (b) EBSD phase map (overlay of image-quality (IQ) map and phase map; high IQ: bright red and bright green; low IQ: dark red and dark green. In this way, one can distinguish between nitrogen ferrite ( $\alpha$; bright red in (b)) and (strained) nitrogen martensite $\left(\alpha^{\prime}\right.$; dark red in (b)). The surface region consists predominantly of f.c.c. nitrogen austenite $(\gamma$, green) succeeded at increasing depth below the surface by b.c.t. nitrogen martensite ( $\alpha^{\prime}$, dark red) and at still larger depths, by b.c.c. ferrite ( $\alpha$, bright red). (c) EBSD phase map (overlay of IQ map and phase map) at higher magnification than in (b) recorded from the surface adjacent region. The local nitrogen concentrations in the matrix surrounding the pores, as determined by EPMA, have been indicated in the figure. It follows that both f.c.c. nitrogen austenite and b.c.t. nitrogen martensite surround the pores (black regions).

specimens ( $c f$. data for the diffusion coefficient of nitrogen in ferrite as given in Reference 12); the homogeneity of the nitrided ferrite matrix was confirmed by the observed constant hardness level over the complete thickness of the $1.0 \mathrm{~mm}$ thick specimens as measured on cross-sections.

The ferrite matrix of the nitrided pure $\alpha$-Fe and nitrided Fe-Me alloys, with interstitially dissolved nitrogen, is thermodynamically unstable underneath the surface with respect to decomposition into nitrogen-depleted ferrite and molecular $\mathrm{N}_{2}$ gas ( $c f$. reaction [4] in Section II and Figure 8). Evidently, pores filled with $\mathrm{N}_{2}$ gas start to develop at grain boundaries (Figure 2). Upon prolonged nitriding these pores coalesce, leading to the appearance of channels i.e., open grain boundaries (e.g., see Figures 2(c) and (e)). From a comparison of nitrided single crystalline and polycrystalline iron specimens ( $c f$. Figure 4 ) it follows that the grain boundaries are essential agents for the nucleation and growth of pores in nitrided ferrite; no pore formation within ferrite grains occurs. Indeed, the driving force for the decomposition of $\alpha-\mathrm{Fe}[\mathrm{N}]$ is relatively small (see Figure 8), so that homogenous nucleation of $\mathrm{N}_{2}$ gas filled pores within the grains may be obstructed. This contrasts with the development of pores in $\varepsilon$-iron nitride.

The nitrogen uptake recorded for the nitrided, polycrystalline pure iron specimen amounts to 0.31 at. pct (cf. Table IV) and thus is slightly smaller than the equilibrium value of the nitrogen solubility of iron as predicted for the employed nitriding conditions (0.35 at. pct according to Reference 19). This difference can be explained by the formation of pores (possibly coalesced to channels) in contact with the outer atmosphere ( $c f$. Figures 2(a) and 4(a)) and the thus occurring nitrogen depletion of the ferrite matrix surrounding these pores/channels ( $c f$. Eq. [4]). Nitrogen uptakes well above the maximum nitrogen solubility of ferritic pure iron occur in case of the $\mathrm{Fe}-\mathrm{Cr}$ and $\mathrm{Fe}-\mathrm{Al}$ alloys, which can be attributed to the development of $\mathrm{AlN}$ and $\mathrm{CrN}$ precipitates, respectively, in the ferrite matrix.

Pore formation in nitrided $\mathrm{Fe}-\mathrm{Al}$ and $\mathrm{Fe}-\mathrm{Cr}$ alloys can be discussed as follows. (i) The (metastable) equilibrium amount of dissolved nitrogen in the ferrite matrix of nitrided iron-based $\mathrm{Fe}-\mathrm{Al}$ and $\mathrm{Fe}-\mathrm{Cr}$ alloys can in principle 

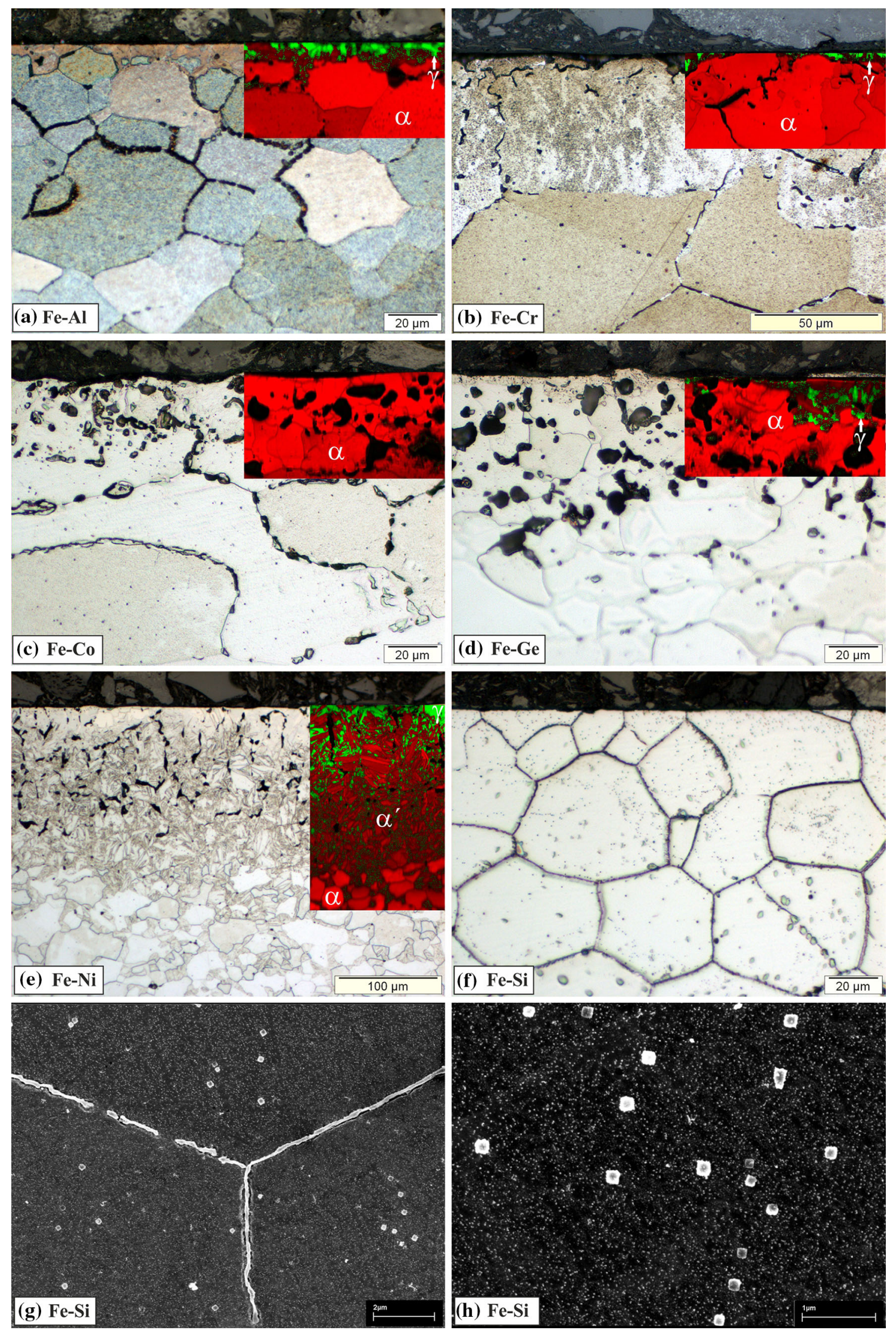
Fig. 6-Microstructures for nitrogen-austenite stabilizing conditions. Micrographs are recorded from cross-sections (polished and etched) of iron-based Fe-Me alloy specimens after nitriding for $72 \mathrm{~h}$ at $923 \mathrm{~K}\left(650^{\circ} \mathrm{C}\right)$ and with $r_{\mathrm{N}}=0.104 \mathrm{~atm}^{-1 / 2}$. ( $a$ through $\left.f\right)$ Light optical micrographs with inserted EBSD phase maps (overlay of IQ map and phase map; $c f$. caption of Fig. 5) where $\alpha$ (bright red), $\alpha^{\prime}$ (dark red), and $\gamma$ (green) denotes nitrogen ferrite, nitrogen martensite, and nitrogen austenite, respectively. $(g, h)$ SEM micrographs recorded from the nitrided $\mathrm{Fe}-\mathrm{Si}$ alloy, which remained ferritic upon nitriding. The amount of pores is small in the $\mathrm{Fe}-\mathrm{Al}$ and $\mathrm{Fe}-\mathrm{Cr}$ alloys, moderate in the Fe-Ni alloy, and large in the Fe-Co and $\mathrm{Fe}-\mathrm{Ge}$ alloys. No pore formation is observable in case of the Fe-Si alloy; $\mathrm{Si}_{3} \mathrm{~N}_{4}$ bands occur along ferrite grain boundaries and cubical $\mathrm{Si}_{3} \mathrm{~N}_{4}$ precipitates are present within ferrite grains (see text).

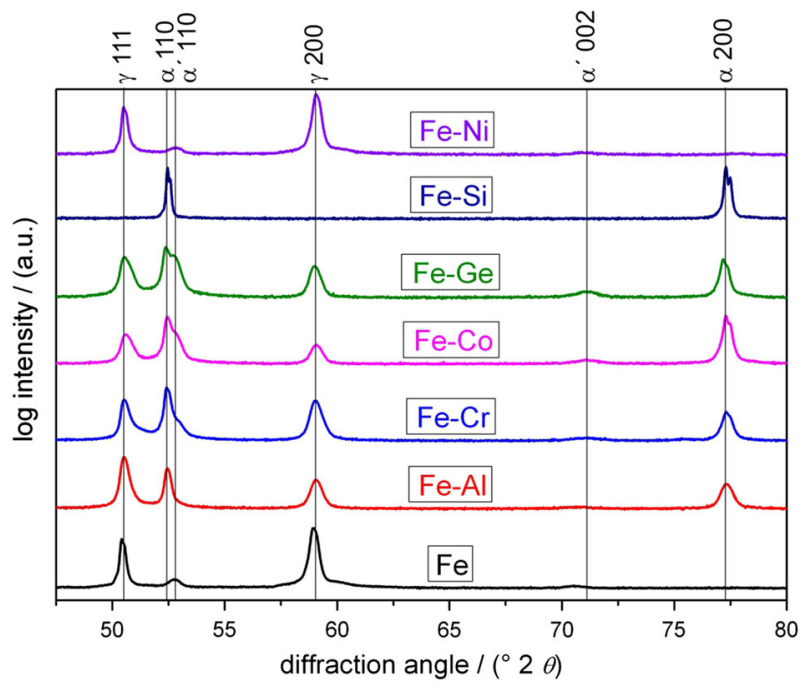

Fig. 7-X-ray diffractograms $\left(\mathrm{Co}-\mathrm{K}_{\alpha}\right)$ recorded from the surface polycrystalline pure $\mathrm{Fe}$ specimen and iron-based $\mathrm{Fe}-\mathrm{Me}$ alloys after nitriding for $72 \mathrm{~h}$ at $923 \mathrm{~K}\left(650{ }^{\circ} \mathrm{C}\right)$ and with $r_{\mathrm{N}}=0.104 \mathrm{~atm}^{-1 / 2}$. The diffractograms of all nitrided Fe-Me alloys show reflections from nitrogen austenite $(\gamma)$ and nitrogen martensite $\left(\alpha^{\prime}\right)$, with the exception of the diffractogram of the Fe-Si alloy, which shows only ferrite reflections.

be larger than that for nitrided pure iron, due to (a) a higher nitrogen solubility in iron-based $\mathrm{Fe}-\mathrm{Al}^{[31]}$ and $\mathrm{Fe}-\mathrm{Cr}$ alloys $^{[32]}$ as compared to pure iron and (b) the presence of so-called excess nitrogen taken up in the strain fields surrounding the MeN-precipitates. ${ }^{[3-35]}$ (ii) Moreover, the development of $\mathrm{AlN}^{\dagger}$ and $\mathrm{CrN}$ precipitates in $\mathrm{Fe}-\mathrm{Al}$ and

${ }^{\dagger}$ Nitriding of iron-based $\mathrm{Fe}-\mathrm{Al}$ alloy at a lower temperature $(823 \mathrm{~K}$ $\left.\left(550^{\circ} \mathrm{C}\right)\right)$ than that in the current study $\left(923 \mathrm{~K}\left(650^{\circ} \mathrm{C}\right)\right)$ leads, prior to the precipitation of hexagonal AIN, to the formation of pores along ferrite grain boundaries due to the large nitrogen supersaturation of the ferrite matrix and the difficult, and thus slow precipitation of hexagonal AIN. In a later stage, the coalesced pores ("microcracks") are closed due to the planar state of high compressive stresses, parallel to the surface, induced by precipitated AlN ${ }^{[17]}$. The pores which are present in the current Fe-Al alloy have developed after AlN precipitation.

Fe-Cr alloys upon nitriding competes with the development of $\mathrm{N}_{2}$ gas containing pores. Hence, it is concluded from (i) and (ii) that the pore fractions in nitrided $\mathrm{Fe}-\mathrm{Al}$ and $\mathrm{Fe}-\mathrm{Cr}$ alloys can be smaller than in nitrided pure iron,

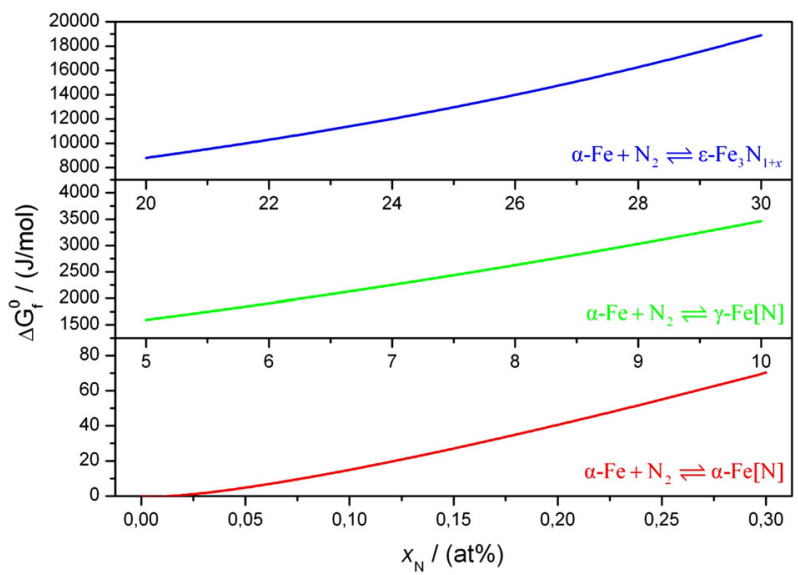

Fig. 8-The Gibbs energies of formation, $\Delta G_{\mathrm{f}}^{0}$ (at $298 \mathrm{~K}\left(25^{\circ} \mathrm{C}\right)$ and $1 \mathrm{~atm}$ ), from $1 \mathrm{~mol}$ ferrite, $\alpha-\mathrm{Fe}$, and the corresponding amount of nitrogen gas, as a function of the nitrogen content, $x_{\mathrm{N}}$, in the nitrogen ferrite $(\alpha-\mathrm{Fe})$, nitrogen austenite $(\gamma-\mathrm{Fe})$ and the $\varepsilon-\mathrm{Fe}_{3} \mathrm{~N}_{1+x}$. Clearly, $\Delta G_{\mathrm{f}}^{0}$ is positive for all three reactions and increases significantly with the nitrogen content in the product phases concerned. Evidently, the three phases considered are all unstable with respect to decomposition. The driving force for this decomposition increases in the order $\alpha-\mathrm{Fe} \rightarrow \gamma$ - $\mathrm{Fe} \rightarrow \varepsilon-\mathrm{Fe}_{3} \mathrm{~N}_{1+x}$, irrespective of the nitrogen content in the range of possible nitrogen content for each phase. For all phases, the driving force for decomposition increases with increasing nitrogen content. Values for $\Delta G_{\mathrm{f}}^{0}$ were calculated using the Thermo-Calc software ${ }^{[22]}$ adopting the thermodynamic model for nitrogen in iron presented in Ref. [23].

as observed ( $c f$. Table IV). Note that the presence of dissolved excess nitrogen in nitrided $\mathrm{Fe}-\mathrm{Al}$ and $\mathrm{Fe}-\mathrm{Cr}$ alloys after the nitriding only seemingly suggests a higher driving force for pore development than in pure iron: this excess nitrogen is thermodynamically stabilized by the misfit-strain fields surrounding the $M e$-nitride precipitates. ${ }^{[33]}$ However, if upon continued nitriding, a coherent $\rightarrow$ incoherent transition sets in for the initially precipitated $M e$-nitrides in the surface adjacent region, then the nitride/ matrix misfit is no longer (fully) accommodated elastically and the capacity for dissolving excess nitrogen gets lost. The originally dissolved excess nitrogen then tends to precipitate and $\mathrm{N}_{2}$ gas filled pores can develop at grain boundaries. This effect has been observed in Reference 36 .

Pore formation in nitrided Fe-Co and Fe-Ge alloys can be discussed as follows. The Fe-Co and Fe-Ge alloys show a nitrogen uptake much smaller than that of the $\mathrm{Fe}-\mathrm{Al}$ and $\mathrm{Fe}-\mathrm{Cr}$ alloys ( $c f$. Table IV) and even smaller than that of pure iron. (i) $\mathrm{Co}^{[37]}$ and $\mathrm{Ge}^{ \pm}$dissolved in $\alpha$ -

${ }^{*}$ In the absence of literature data, the relatively low nitrogen solubility of ferritic Fe-Ge alloy was demonstrated by the following additional experiments performed in this project: Foils from pure iron and $\mathrm{Fe}-\mathrm{Ge}$ alloy were prepared with a thickness of $0.2 \mathrm{~mm}$ and the lateral dimensions of $(15 \times 10) \mathrm{mm}^{2}$. Specimens, cut from these foils, were recrystallized at $800{ }^{\circ} \mathrm{C}$ for $20 \mathrm{~min}$ and subjected to nitriding at $580^{\circ} \mathrm{C}$ with $r_{\mathrm{N}}=0.104 \mathrm{~atm}^{-1 / 2}$ for $15 \mathrm{~h}$. This lower nitriding temperature [as compared to $923 \mathrm{~K}\left(650^{\circ} \mathrm{C}\right)$ ] was chosen to retard pore formation and the chosen time was found to be sufficient to homogenously (through) nitride these $0.2-\mathrm{mm}$-thick foils and to avoid pore formation. The nitrogen equilibrium concentration after nitriding was determined for the pure iron to be 0.30 at. pct and for the Fe-Ge alloy to be only 0.19 at. pct. 
Fe lower the nitrogen solubility of the ferrite. Extremely high nitriding potentials are necessary to form Co and Ge nitrides: see Reference 38 for a Lehrer-type diagram for the Co-N system and note the extremely large volume misfit of $\mathrm{Ge}_{3} \mathrm{~N}_{4}$ with the ferrite matrix, as given in Table IV. (ii) In nitrided Fe-Co and Fe-Ge alloys, the formation of $\mathrm{N}_{2}$ gas filled pores can occur in the absence of competition with $M e$-nitride precipitation. Hence, it is concluded from (i) and (ii) that pore fractions in nitrided Fe-Co and Fe-Ge alloys can be (much) higher than in nitrided pure iron, as observed ( $c f$. Table IV).

$\mathrm{Si}$ as an alloying element in iron lowers, similar as $\mathrm{Co}$ and $\mathrm{Ge}$, the equilibrium nitrogen solubility in ferrite. ${ }^{[39]}$ Although, as compared with the Fe-Ge system (where no Me-nitride development was observed at all upon nitriding), for the Fe-Si system the chemical driving force for Me-nitride precipitation is larger and the nitride/matrix misfit is smaller (but still very large; see Table IV), yet, but only after very long nitriding times, (amorphous instead of crystalline) silicon-nitride precipitates develop in the ferrite matrix grains (see References 40 through 42 and Figure 6(g)). On this basis, and with reference to the above discussion on nitrided Fe-Co and Fe-Ge alloys, one might expect a pore fraction of value as observed for $\mathrm{Fe}-\mathrm{Co}$ and $\mathrm{Fe}-\mathrm{Ge}$ alloys. Instead, a pore fraction is observed that is even distinctively smaller than that for pure iron. Recognizing that in ferritic pure iron and ferritic Fe-Me alloys the grain boundaries act as the only nucleation agents for the $\mathrm{N}_{2}$ gas filled pores (see Figure 2, Section IV-A and above), this peculiar phenomenon is interpreted as follows. $\mathrm{Si}_{3} \mathrm{~N}_{4}$ precipitates as amorphous bands along the ferrite matrix grain boundaries, prior to precipitation of (cubical) $\mathrm{Si}_{3} \mathrm{~N}_{4}$ particles within the ferrite matrix grains. ${ }^{[41]}$ It is suggested that these amorphous bands hinder the nucleation of pores at grain boundaries, which are the agents for nucleation of $\mathrm{N}_{2}$ gas filled pores in ferritic material, as discussed above, (also) because by formation of these bands the nitrogen otherwise available for pore formation is consumed.

The relatively high amount of nitrogen taken up by the Fe-Ni alloy specimen (0.99 at. pct) is due to the development of nitrogen austenite (so the specimen did not remain ferritic as the other alloys nitrided subject to the same conditions; $c f$. Figure 3); it cannot be ascribed to the development of nickel nitride: extremely high nitriding potentials, which are not applied in this work, are required to stabilize nickel nitrides. ${ }^{[43]}$ Upon water quenching to room temperature, nitrogen austenite transforms to nitrogen martensite provided its nitrogen content is not too high (martensite start temperature, $M_{\mathrm{s}}$, of pure $\mathrm{Fe}[\mathrm{N}]$ is above RT for a nitrogen content larger than 8.4 at. $\mathrm{pct}^{[44]}$ ). The austenite stabilization observed upon nitriding for the originally ferritic Fe-Ni alloy in the surface adjacent region is the result of the combined austenite stabilization effects of both dissolved nitrogen and dissolved $\mathrm{Ni}$ (evidently, only the 2 at. pct $\mathrm{Ni}$ in the considered $\mathrm{Fe}-\mathrm{Ni}$ alloy cannot stabilize the austenite phase at the nitriding temperature of $923 \mathrm{~K}\left(650^{\circ} \mathrm{C}\right)$, according to the data presented in Reference 45$)$.
The high $\mathrm{N}_{2}$ gas pressures which would develop in the closed pores cannot be sustained by surrounding matrix ( $c f$. Section II). Thus, pore formation is associated with plastic yielding of the surrounding ferrite matrix: the diameters of the pores at the grain boundaries in the polycrystalline specimens are several microns and it appears that, under the action of the $\mathrm{N}_{2}$ gas pressure in closed pores in the subsurface region, the specimen surface can (even) bulge out (Figures 4(a), (c) and (d)) by plastic yielding of the ferrite matrix surrounding the pores.

Precipitation of alloying-element nitrides significantly strengthens the ferrite matrix which, in view of the discussion in the above paragraph, can then retard pore growth. Hence, not only pore nucleation is less abundant in the case of alloying elements which easily precipitate as nitrides (due to a smaller chemical driving force for pore formation in the beginning of nitriding; see above discussion), but also the subsequent pore growth is retarded.

\section{B. Pore Formation in Nitrogen Austenite and the Role of Alloying Elements}

The microstructure developing upon nitriding an (initially ferritic) pure iron specimen, employing conditions which stabilize nitrogen austenite, $\gamma$-Fe[N], at the specimen surface $\left(923 \mathrm{~K}\left(650{ }^{\circ} \mathrm{C}\right), r_{\mathrm{N}}=0.104 \mathrm{~atm}^{-1 / 2}\right)$, can be understood as follows (see Figure 5). Nucleation of nitrogen austenite can occur at the moment that the nitrogen concentration in ferrite at the surface exceeds that of the ferrite/austenite phase boundary in the Fe-N phase diagram. Continued nitriding leads to a thickness increase of this formed nitrogen-austenite layer by migration of the $\alpha / \gamma$ transformation front in the direction of the specimen's core. The here applied nitriding time of 72 hours at $923 \mathrm{~K}\left(650{ }^{\circ} \mathrm{C}\right)$ is not sufficient for the complete transformation of the $1.0-\mathrm{mm}$-thick specimen into nitrogen austenite, and thus the specimens were not homogenously (through) nitrided (the core region of the specimens remained ferritic; the core region is saturated with nitrogen; a hardness measurements in the core region revealed a hardness $\left(200 \mathrm{HV}_{0.1}\right)$ which is twice that of unnitrided pure ferrite), in contrast with the nitrided ferritic specimens discussed in Section V-A.

Similar as discussed for nitrogen ferrite (Section VA), the nitrogen austenite underneath the surface is thermodynamically unstable with respect to decomposition into nitrogen-depleted austenite and molecular $\mathrm{N}_{2}$ gas ( $c f$. reaction [5a] in Section II and Figure 8). As a consequence, porosity develops along the grain boundaries of austenite in the subsurface regions. Prolonged nitriding leads to the coalescence of pores to channels which can be in direct contact with the nitriding outer atmosphere $\left(\mathrm{NH}_{3} / \mathrm{H}_{2}\right.$-gas mixture). (Subsequent) Decrease of the nitrogen concentration in nitrogen austenite adjacent to the pores can eventually lead to the reemergence of ferrite, as reported in an earlier investigation. ${ }^{[14]}$

In the current work, pores which have developed upon nitriding at austenite grain boundaries are, 
according to the EBSD and EPMA measurements (see Figure 5(c)), surrounded by nitrogen austenite (and/or nitrogen martensite after quenching). The nitrogen concentrations in the vicinity of pores (see Figure 5(c)) are too high for the presence (by reemergence as discussed above or by direct decomposition according to reaction [5b]) of a possible ferrite phase (the maximum solubility of nitrogen in ferrite at $923 \mathrm{~K}\left(650{ }^{\circ} \mathrm{C}\right)$ amounts to approx. 0.27 at. $\mathrm{pct}^{[23]}$ ). As shown in Section II, the value of the Gibbs reaction energy of the decomposition reaction [5a] of nitrogen austenite into nitrogen-depleted nitrogen austenite and $\mathrm{N}_{2}$ gas is negative, whereas the decomposition reaction [5b] of nitrogen austenite into nitrogen-depleted ferrite and $\mathrm{N}_{2}$ gas is only thermodynamically possible until an inner pore $\mathrm{N}_{2}$ gas pressure of $330 \mathrm{MPa}$ has been attained. Therefore, the occurrence of nitrogen ferrite, as a direct decomposition product of nitrogen austenite, is at the $\mathrm{N}_{2}$ gas pressures in the pores where yielding of the surrounding matrix occurs (380 MPa; $c f$. Section II) inhibited.

The EBSD phase map (Figure 5(b)) shows nitrogen austenite concentrated close to the surface of the nitrided and quenched iron specimen. The martensite start temperature $\left(M_{\mathrm{s}}\right)$ depends on the nitrogen concentration (the higher the nitrogen concentration the lower is $M_{\mathrm{s}}^{[44]}$ ). Nitrogen austenite regions at the very surface contain the highest nitrogen content and thus the lowest $M_{\mathrm{s}}$. For the employed nitriding conditions, the expected surface nitrogen concentration is 9.5 at. pct $^{[23,25]}$ which corresponds to a $M_{\mathrm{s}}$ temperature of approx. $-323 \mathrm{~K}$ $\left(-50{ }^{\circ} \mathrm{C}\right) \cdot{ }^{[44]}$ Consequently, the nitrogen austenite phase close to the surface, i.e., the nitrogen austenite with the highest nitrogen content in the specimen, is preserved upon quenching to room temperature.

Similar to pore formation in nitrogen-ferrite specimens, the pore formation tendency is lower for the $\mathrm{Fe}$ Me alloys with alloying elements which more or less easily precipitate as nitrides (i.e., $\mathrm{Me}=\mathrm{Al}, \mathrm{Cr}$, and $\mathrm{Si}$ ) and the pore formation tendency is higher for alloying elements which cannot precipitate, in the practice of the current experiments, as alloying-element nitrides (i.e., $\mathrm{Me}=\mathrm{Co}, \mathrm{Ge}$, and $\mathrm{Ni}$ ).

The non-occurrence of nitrogen austenite (at the surface), in the case of the nitrided Fe-Si alloy (Figures 6 and 7), can be ascribed to Si being the strongest ferrite stabilizing alloying element, as compared to $\mathrm{Co}, \mathrm{Ni}$, and Ge.

Nitrided Fe-Ni alloy shows a microstructure which is comparable to the microstructure of nitrided pure iron (cf. Figures 5(a) and 6(e)). A pronounced layer of nitrogen martensite with a thickness of approximately $200 \mu \mathrm{m}$ (see what follows) is visible in the light optical micrograph and the EBSD phase map inset (see Figure 6(e)).

The thickness of the nitrogen austenite/martensite layers is much smaller in the $\mathrm{Fe}-\mathrm{Me}$ alloys which are alloyed with ferrite stabilizing alloying elements such as $\mathrm{Al}, \mathrm{Cr}$, and $\mathrm{Ge}$ ( $\mathrm{Ni}$ is an austenite stabilizing element). Also the occurrence of pronounced pore development, as in case of the $\mathrm{Fe}-\mathrm{Co}$ alloy, obstructs growth of the nitrogen-austenite layer, because the nitrogen that could be used for nitrogen-austenite layer growth gets lost by pore development.

The attainable nitrogen supersaturation in austenite is much larger than in ferrite ( $c f$. Section II), which promotes pore nucleation, but this is counteracted by a nitrogen diffusion rate in austenite being much slower than in ferrite (a factor 1000 at $923 \mathrm{~K}\left(650^{\circ} \mathrm{C}\right)^{[46,47]}$ ). Especially if the growth rate of the nitrogen-austenite layer into ferrite is (partly) interface controlled, then the growth rate is (also) controlled by the difference in Gibbs energy of ferrite and austenite. ${ }^{[48]}$ In case of ferrite stabilizing alloying elements, as $\mathrm{Al}, \mathrm{Cr}$, and $\mathrm{Ge}$, this difference in Gibbs energy will be relatively small, which would lead to a reduced rate of austenite layer growth. This is observed indeed for $\mathrm{Fe}-\mathrm{Al}, \mathrm{Fe}-\mathrm{Cr}$, and $\mathrm{Fe}-\mathrm{Ge}$ alloys compared to pure Fe (cf. Figures 6(a), (b) and (d) vs 5(a)). In such cases the ferrite matrix underneath the relatively slowly growing austenite layer will become more rapidly supersaturated with nitrogen. Indeed for the same time of nitriding, at identical nitriding conditions, porosity in the ferrite underneath the austenite layer is observed for $\mathrm{Fe}-\mathrm{Al}, \mathrm{Fe}-\mathrm{Cr}$, and $\mathrm{Fe}-$ Ge alloys and not for pure Fe (see, Figures 6(a), (b) and (d) vs 5a).

\section{CONCLUSIONS}

- The thermodynamic instability of pure nitrogen ferrite can in principle induce its decomposition in nitrogen-depleted ferrite and nitrogen gas. This nitrogen gas development leads to the formation of pores at grain boundaries, as shown in this project for the nitrided ferrite matrix of pure iron. Strikingly, a single crystal of nitrided, pure ferritic iron did not show porosity development.

- The nitrogen gas pressure in closed pores exceeds the critical value for yielding according to both the von Mises criterion and the Tresca criterion, and the matrix surrounding the pores visibly yields as, for example, exhibited by bulging out of the specimen surface.

- The thermodynamic instability of pure nitrogen austenite induces its decomposition in nitrogen-depleted austenite and nitrogen gas leading to pore development similar as in nitrogen ferrite. The driving force for this process is much larger than for the decomposition of nitrogen ferrite. The decomposition of nitrogen austenite into nitrogen ferrite and $\mathrm{N}_{2}$ gas is thermodynamically possible, but the release of Gibbs energy is small in comparison with the decomposition of nitrogen austenite into nitrogen-depleted austenite and $\mathrm{N}_{2}$ gas. The ferrite phase can reemerge if the nitrogen depletion of the austenite, surrounding channels (at grain boundaries) in contact with the outer surface, continues.

- Alloying elements that enhance the nitrogen equilibrium solubility in iron, i.e., $\mathrm{Al}$ and $\mathrm{Cr}$, and that precipitate easily as nitrides, such as $\mathrm{AlN}$ and $\mathrm{CrN}$, 
exhibit less pronounced pore formation than pure iron.

- Alloying elements that reduce the nitrogen equilibrium solubility in iron, i.e., Co and Ge, and that do not precipitate easily as nitrides, promote the formation of pores as compared to pure iron.

- Si dissolved in iron lowers the nitrogen equilibrium solubility in iron and precipitates (very slowly) as (amorphous) $\mathrm{Si}_{3} \mathrm{~N}_{4}$. The pore formation at ferrite grain boundaries is retarded due to the development of amorphous $\mathrm{Si}_{3} \mathrm{~N}_{4}$ bands along the grain boundaries which inhibits nucleation of $\mathrm{N}_{2}$ gas filled pores at the grain boundaries.

\section{ACKNOWLEDGMENTS}

The authors thank Mr. Dipl.-Ing. (FH) P. Kress and Mr. W. Engelhardt for assistance with the nitriding experiments, Dr. E. Bischoff for EBSD investigation and discussion, Dipl.-Ing. P. J. Rossi for SEM investigation and Mrs. S. Haug for EPMA analysis (all with the Max Planck Institute for Intelligent Systems, Stuttgart).

\section{REFERENCES}

1. E.J. Mittemeijer: in ASM Handbook, vol. 4A, J.I. Dossett and G.E. Totten, eds., 2013, pp. 619-46.

2. D. Liedtke, U. Baudis, J. Boßlet, U. Huchel, H. Klümper-Westkamp, W. Lerche, and H.-J. Spies: Wärmebehandlung von Eisenwerkstoffen, 3rd ed., Expert-Verlag, Renningen-Malmsheim, 2006.

3. P.M. Unterweiser and A.G. Gray, eds.: Source Book on Nitriding, ASM, Metals Park, OH, 1977.

4. H.C.F. Rozendaal, E.J. Mittemeijer, P.F. Colijn, and P.J. van der Schaaf: Metall. Trans. A, 1983, vol. 14A, pp. 395-99.

5. S.R. Meka and E.J. Mittemeijer: JOM, 2013, vol. 65 (6), pp. 769-75.

6. B. Prenosil: HTM, 1973, vol. 28, pp. 157-64.

7. M.A.J. Somers and E.J. Mittemeijer: Surf. Eng., 1987, vol. 3 (2), pp. 123-37.

8. M.A.J. Somers, B.J. Kooi, W.G. Sloof, and E.J. Mittemeijer: Surf. Interface Anal., 1992, vol. 19 (1-12), pp. 633-37.

9. R. Hoffmann, E.J. Mittemeijer, and M.A.J. Somers: HTM, 1996, vol. 51, pp. 162-69.

10. C. Middendorf and W. Mader: Z. Metallkd., 2003, vol. 94 (3), pp. $333-40$.

11. I. Etsion: J. Tribol-T ASME, 2005, vol. 127, pp. 248-53.

12. E.J. Mittemeijer and M.A.J. Somers: Surf. Eng., 1997, vol. 13 (6), pp. 483-97.

13. E. Lehrer: Z. Elektrochem., 1930, vol. 36, pp. 383-92.

14. E.J. Mittemeijer, M. van Rooyen, I. Wierszyllowski, H.C.F. Rozendaal, and P.F. Colijn: Z. Metallkd., 1983, vol. 74 (7), pp. 473-83.

15. F.X. Lu: Inst Phys. Conf. Ser. No. 68, Chapter 9, 1983.

16. E.J. Mittemeijer: J. Met., 1985, vol. 37 (9), pp. 16-20.

17. S.R. Meka, S.S. Hosmani, A.R. Clauss, and E.J. Mittemeijer: Int. J. Mater. Res., 2008, vol. 99 (7), pp. 808-14.
18. S.S. Hosmani, R.E. Schacherl, and E.J. Mittemeijer: Acta Mater., 2006, vol. 54 (10), pp. 2783-92.

19. J. Stein, R.E. Schacherl, M. Jung, S.R. Meka, B. Rheingans, and E.J. Mittemeijer: Int. J. Mater. Res., 2013, vol. 104 (11), pp. 1053-65.

20. E.J. Mittemeijer and J.T. Slycke: Surf. Eng., 1996, vol. 12 (2), pp. $152-62$.

21. M. Yu, G. Ma, and J. Li: Structural Plasticity: Limit, Shakedown and Dynamic Plastic Analyses of Structures, Springer Books, New York, 2009.

22. J.O. Anderson, T. Helander, L. Höglund, P.F. Shi, and B. Sundman: CALPHAD, 2002, vol. 26, pp. 273-312.

23. J. Kunze: $H T M, 1996$, vol. 51 (6), pp. 348-54.

24. K.D. Clarke, R.J. Comstock, Jr., M.C. Mataya, C.J. Tyne, and D.K. Matlock: Metall. Mater. Trans. A, 2008, vol. 39A, pp. $752-62$.

25. M.W. Chase Jr.: J Phys Chem Ref Data, Monograph 9, 1998, http://webbook.nist.gov, Accessed November 2013.

26. M.O. Speidel: Proc Stainless Steel World 2001 Conference, The Hague, The Netherlands, 2001.

27. M.L.G. Byrnes, M. Grujicic, and W.S. Owen: Acta Metall. Mater., 1987, vol. 35 (7), pp. 1853-62.

28. JCPDS: PDF-2 (2002) database. Version 2.1, International Center for Diffraction Data, 2002.

29. R.T. DeHoff and F.N. Rhines: Quantitative Microscopy, McGrawHill, New York, 1968

30. J.L. Pouchou and F. Pichoir: Rech Aerospatiale, 1984, no. 3, pp. 167-92.

31. A.H. Jehn and P. Perrot: Aluminum-Iron-Nitrogen, LandoltBörnstein New Series IV/11D1, Accessed November 2013.

32. P. Perrot: Chromium-Iron-Nitrogen, Landolt-Börnstein New Series IV/11D3, http://www.springermaterials.com, Accessed November 2013.

33. M.A.J. Somers, R.M. Lankreijer, and E.J. Mittemeijer: Philos. Mag. A, 1989, vol. 59 (2), pp. 353-78.

34. M.H. Biglari, C.M. Brakman, E.J. Mittemeijer, and S. van der Zwaag: PhilosMag. A, 1995, vol. 72 (4), pp. 931-47.

35. R.E. Schacherl, P.C.J. Graat, and E.J. Mittemeijer: Metall. Mater. Trans. A, 2004, vol. 35A, pp. 3387-98.

36. P.M. Hekker, H.C.F. Rozendaal, and E.J. Mittemeijer: J. Mater. Sci., 1985, vol. 20 (2), pp. 718-29.

37. S.Y. Zaginaychenko, Z.A. Matysina, and M.I. Milyan: Fiz. Met. Metalloved, 1990, vol. 22, pp. 63-67.

38. A. Leineweber, F. Lienert, S. Glock, T. Woehrle, P. Schaaf, M. Wilke, and E.J. Mittemeijer: Z. Kristallogr. Proc., 2011, vol. 1, pp. 293-98.

39. J. Kunze and P.O.K. Friedrich: J. Mater. Sci. Lett., 1986, vol. 5 (8), pp. 815-18.

40. E.J. Mittemeijer, M.H. Biglari, A.J. Bottger, N.M. van der Pers, W.G. Sloof, and F.D. Tichelaar: Scripta Mater., 1999, vol. 41 (6), pp. $625-30$.

41. S.R. Meka, K.S. Jung, E. Bischoff, and E.J. Mittemeijer: Philos. Mag., 2012, vol. 92 (11), pp. 1435-55.

42. H.P. van Landeghem, M. Goune, and A. Redjaimia: Steel Res. Int., 2012, vol. 83 (6), pp. 590-93.

43. M. Fonovic, A. Leineweber, and E.J. Mittemeijer: Surf. Eng., 2013, vol. 30, pp. 16-20.

44. T. Bell and W.S. Owen: Trans. Metall. Soc. AIME, 1967, vol. 239 (12), p. 1940

45. Fe-Ni (Iron-Nickel), The Landolt-Börnstein Database IV/5, Springer Materials, http://www.springermaterials.com, Accessed November 2013

46. J.D. Fast and M.B. Verrijp: J. Iron Steel. Ins., 1954, vol. 176 (1), pp. 24-27.

47. H.J. Grabke and E.M. Petersen: Scripta Metall., 1978, vol. 12 (12), pp. 1111-14.

48. E.J. Mittemeijer: Fundamentals of Materials Science, SpringerVerlag, Berlin, 2010. 